\title{
Çalışanların Yaşam Doyumuna Yönelik Algıları, Örgütsel Özdeşleşme Düzeyleri ve Akış Deneyimi Arasındaki İlişkiler: Bilişim Sektörü Örneği ${ }^{1}$
}

\author{
DOI: $10.26466 /$ opus.583983 \\ * \\ Cemalettin Öcal Fidanboy* \\ *Dr, Fidanboy Danışmanlık / Ankara / Türkiye \\ E-Posta: ocalfidanboy@hotmail.com \\ ORCID: $\underline{0000-0001-8963-0778}$
}

Öz

Bu araştırmada; bilişim sektöründe görev yapan çalışanların yaşam doyumuna yönelik algılarl, örgütsel özdeşleşme düzeyleri ve akış deneyimine yatkınlıkları arasındaki ilişkilerin belirlenmesi amaçlanmıştır. Hayatın olumlu yönlerine odaklanan ve belirlediği hedeflere ulaşma konusunda uyumlu davranışlar sergileyen çalışanların, iş yaşamında daha fazla örgütsel özdeşleşme davranışları sergileyebilecekleri ve iş yaşamında akış deneyimi yaşamaya daha yatkın olabilecekleri varsayılmıştır. Bu amaç doğrultusunda, Teknopark toplulukları bünyesinde ve bilişim sektöründe çalışan 214 personelden kolayda örnekleme yöntemiyle veriler toplanmıştır. Toplanan veriler kapsamında güvenilirlik analizleri, doğrulayıcı faktör analizleri yapılmış, değişkenler arasındaki korelasyon ilişkileri belirlenmiş ve değişkenler arasındaki ilişkileri ortaya koymak üzere yapısal eşitlik modellemesi yöntemi kullanılarak detaylı analiz çalışmaları gerçekleştirilmiştir. Araştırmadan elde edilen bulgular, bilişim sektöründe görev yapan çalışanların yaşam doyumlarıla örgütsel özdeşleşme düzeyleri arasında anlamlı bir korelasyon ilişkisinin bulunmadığını, bununla birlikte akış deneyimi ve örgütsel özdeşleme arasında anlamlı bir iliş̧kinin ve etkinin olduğunu göstermiş̧ir. Çalışma aynı zamanda bilişim sektöründe yaşanan akış deneyimiyle yaşam doyumu arasındaki ilişkilere de işaret etmektedir.

Anahtar Kelimeler: Yaşam doyumu, Örgütsel özdeşleşme, Akış deneyimi, Bilişim sektörü.

\footnotetext{
${ }^{1}$ Bu çalışmanın bir kısmı 2-4 Mayıs 2019 tarihlerinde Osmaniye Korkut Ata Üniversitesi'nde düzenlenen 18. Uluslararası Iş̧letmecilik Kongresi'nde sözlü bildiri olarak sunulmuştur.
} 


\title{
The Relationships among Perceptions of Life Satisfaction, Organizational Identification Levels and Flow Experience of Employees: the Case of Information Technology (IT) Sector
}

\begin{abstract}
In this research, it is aimed to determine the relationships between the perceptions of employees about life satisfaction, organizational identification levels and flow experience based on the employees working in the Information Technology (IT) sector. It is assumed that the employees who focus on the positive aspects of life and exhibit compatible behaviors in terms of achieving the goals they set, may exhibit more organizational identification behaviors and to be more prone to live flow experience in business life. In this respect, data from 214 IT personnel working in Technoparks were collected via convenience sampling method. Within the scope of the data collected; reliability analyzes, confirmatory factor analyzes were made, correlation relationships were determined between the variables and detailed analyzes were performed by structural equation modeling method to reveal the relationships between the variables. Findings from the study showed that there is no significant correlation between life satisfaction and organizational identification levels of employees working in IT sector, but there is a significant relationship and effect between flow experience and organizational identification. The study also points to the relationships between the flow experience and life satisfaction in IT sector.
\end{abstract}

Keywords: Life satisfaction, Organizational identification, Flow experience, Information Technology 


\section{Giriş}

Günümüz iş dünyasında yaşanan gelişmeler, bireyin genel yaşamının çok büyük bir bölümünü iş ortamında geçirmesine neden olmaktadır. Birçok birey için iş yaşamı, yaşanan teknolojik gelişmelerin etkisiyle genel yaşamın merkezinde yer alan bir olgu haline gelmiştir. Birey genel yaşamını yaşarken, kendisini bir anda yoğun bir iş ortamında bulabilmekte ve aktif bir şekilde işe odaklanma ve kendini işe verme konusunda önemli sıkıntılar yaşayabilmektedir. Günümüzün teknolojik olanakları göz önüne alındığında, genel yaşam ve iş yaşamını birbirinden izole kavramlar olarak düşünmek olanaksızdır. Bununla birlikte; genel yaşam ve iş yaşamı arasındaki bu iç içe geçmişlik durumu, genel yaşamından mutluluk duyan ve yaşam kalitesini olumlu olarak değerlendiren bir çalışanın, her koşulda örgütünü sahiplenmesinin ve kendisini örgütün bir parçası olarak hissetmesinin mümkün olabileceğini de gündeme getirmektedir. Konuya bu açıdan bakıldığında; çalışanın genel yaşam doyumu, örgütüyle özdeşleşmesi ve akış deneyimine yatkınlığı arasındaki olası ilişkiler, yönetimsel açılardan değerlendirilmesi gereken önemli olgular olarak dikkat çekmektedir.

Çalışanın işinden elde ettiği tatmin ve kazandığ deneyimler, iş dışındaki genel yaşamı yoğun bir şekilde etkilemektedir (Brayfield vd., 1957). Bir başka deyişle iş yaşamı, çalışma dışı yaşama önemli ölçüde etki eden bir kavramdır. Bireyde yaşam doyumunun oluşmasında, iş yaşamından elde edilen doyumunun büyük katkısı vardır. Aynı zamanda iş doyumu, genel yaşam doyumunun alt bir alanı olarak değerlendirilebilecek bir olgudur (Keser, 2005). İş ortamında yaşanan deneyimler, bireyin genel yaşamını olumlu veya olumsuz yönde etkiler. Aynı şekilde genel yaşam deneyimleri de, iş yaşamında olumlu veya olumsuz etkilere sahiptir. Genel yaşamda edinilen olumlu deneyimlerin iş yaşamını etkilemesi ve bunun sonucunda bireyin görev yaptığı örgütü sahiplenmesi, kendisini örgütün bir parçası gibi hissedebilmesi ve daha yüksek düzeyde örgütsel özdeşleşme davranışı göstermesi de mümkün görünmektedir. Mael ve Ashforth'a (1992) göre örgütsel özdeşleşme, bireyin amaçlarının örgütün amaçlarıyla eşlenik hale gelmesi ve bireyin kendisini örgütün bir parçası 
gibi hissetmesi olarak tanımlanan bir durumdur. Örgütüyle özdeşleşebilen bireyler, örgütünün yaşadığı başarıları veya başarısızlıkları, kendi başarı veya başarısızlıkları olarak algılayabilirler (Ashforth ve Mael, 1989).

Teknolojinin getirdiği olanaklar neticesinde; bir çalışanın genel yaşamını yaşarken kendisini aniden aktif bir iş ortamı içinde bulması, güçlü bir odaklanma ve kendini işe verme yeteneği gerektirir. Bahsi geçen bu güçlü odaklanma yeteneği, örgütsel literatürde akış deneyimine yatkınlık şeklinde tanımlanmaktadır. Csikzentmihalyi (1990), çalışan bir bireyin kendisine içsel bir motivasyon sağlayan ve zor olduğunu hissettiği halde aynı zamanda kontrol altında da tutabildiği görevlerle haşır neşir olduğunda benzersiz bir şekilde yaşadığı psikolojik bir durumdan bahsetmektedir. İş yaşamında akış deneyimi olarak adlandırılan bu psikolojik durumun, yaşam doyumuyla ve bireyin örgütle özdeşlemesiyle de bazı ilişkilerinin söz konusu olabileceği düşünülmektedir. Akış deneyimine yatkın olma durumu keyifli bir deneyim şeklinde tanımlanmakta olup, bireyi olumlu yönde etkilemekte ve iş performansında da önemli avantajlar sağlayabilmektedir (Nakamura ve Csikzentmihalyi, 2005). Çalışan bir bireyin iş yaşamında akış deneyimi yaşamaya yatkın bir davranış sergilemesi, örgütsel özdeşleşmeye ve yaşam doyumu algısına katkı sağlaması açısından oldukça önemlidir. Günümüzdeki teknolojik gelişmelerle birlikte daha fazla önem kazanan içe dönük motivasyon ve odaklanma ihtiyacı, yaşam doyumu ve iş doyumu arasındaki iç içe geçmişlik durumunun verdiği s1kıntıları azaltmak açısından önemli bir reçete haline gelebilir.

Bu çalışma kapsamında; çalışanın yaşam doyumuna yönelik algısı, örgütsel özdeşleşme düzeyi ve akış deneyimine yatkınlığı arasında temel bazı ilişkilerin var olabileceği varsayılmıştır. Araştırmada bilişim sektörü çalışanları esas alınmış ve bu sektördeki bireylerden elde edilen veriler analiz edilerek incelenmiştir. Çalışma için belirlenen kuramsal çerçeve kapsamında; yaşam doyumu, örgütsel özdeşleşme ve akış deneyimi kavramlarına yönelik araştırmalar yapılmış ve bir araştırma modeli oluşturulmuştur. Ardından, belirlenen araştırma modelini temel alan hipotezler üretilmiştir. Hipotezler, bilişim sektörü verilerine dayanılarak sınanmıştır. Araştırmadan elde edilen sonuçlar, bilişim sektörünün temel dinamikleri esas alınarak detaylı bir şekilde tartışılmıştır. 


\section{Kuramsal Çerçeve}

\section{Yaşam Doyumu}

Yaşam doyumu, bireyin mutlu olma hali ve yaşamın bir anlam kazanması için gereken en temel unsurlardan birisi olarak açılanan bir kavramdır (Dağlı ve Baysal, 2016). Birey yaşam doyumu hissederken, hem bireysel özelliklerinin hem de örgütsel dinamiklerin etkisi altında kalmaktadır (Şimşek ve Aktaş, 2014). Bireyin iş motivasyonu ve çalışmaya yönelik isteklerinde; sadece iş doyumunun değil, yaşam doyumunun da önemli katkıları olduğu bilinmektedir (Keser, 2005). Öznel iyi oluşun alt boyutlarından birisi olan yaşam doyumu, bireyin hayatı kendi belirlediği ölçütlere göre olumlu bir şekilde algilama halini ifade eder (Emmons ve Diener, 1985). Bireyin tüm yaşamından beklentilerinin ve isteklerinin karşılanması durumunda, yaşam doyumu olarak ifade edilen durumun oluştuğu söylenebilir. Bireyin kendisi için belirlediği amaçlara ulaşma düzeyinin artması, yaşam doyumunu da arttırmaktadır (Dost, 2007). Yaşam doyumu; mutlu olmak için yaşamdan beklediklerimizi, sahip olduklarımızla karşılaştırdığımızda ortaya çıkan pozitif psikolojik bir durumdur. Diener ve arkadaşları'na (1985) göre yaşam doyumu; bireyin şimdiki yaşamından aldığı doyumu, geçmişte yaşadığ yum hissi ve çevresinin bireyin yaşam doyumuna yönelik değerlendirmelerini içerir. Birey, yaşamdan beklentileri ile mevcutta sahip oldukları arasında bir uyum sağladığında, yaşam doyumunu yoğun bir şekilde hissedebilir. Bununla birlikte içinde yaşanılan ülkenin ekonomik durumu, topluluk içinde bulunma, siyasi kararlılık, toplumda üst gruplarda yer alma, evli ve ailesiyle iyi ilişkiler içinde olma, açık fikirli ve aktif bir yaşam sürme, sağlıklı olma ve sosyal değerlere önem verme gibi kavramların yaşam doyumu üzerinde önemli etkileri vardır (Dockery, 2003).

\section{Örgütsel Özdeşleşme}

Örgütsel özdeşleşme kavramı; çalışanın sosyal bir varlık olarak örgütüyle derin, duygusal ve bilişsel bağlar hissetmesini ifade eden bir kavramdır (Edwards, 2005). Ashforth ve Mael (1989) örgütsel özdeşleşmeyi sosyal kimliğin özel bir formu olarak tanımlar. Yönetim ve örgüt literatüründe 
örgütsel özdeşleşme konusunda çeşitli çalışmaların bulunduğu bilinmektedir (Ashforth ve Mael, 1989; Dutton vd.,1994; Riketta ve Van Dick, 2005; Rousseau, 1998). Örgütsel özdeşleşme; kendi kendine sınıflandırma ve etiketleme, örgütsel amaçlar ve değerleri paylaşma ve çalıştığ 1 örgüte sahiplik, üyelik ve bağlllık duygusu geliştirebilme alt bileşenlerine sahiptir (Edwards ve Peccei, 2007).

Örgütsel özdeşleşme, çalışan bir bireyin amaçlarının görev yaptığı örgütün amaçlarıyla eşlenik bir halde olması ve bireyin kendisini örgütün bir parçası gibi hissetmesi şeklinde tanımlanır (Mael ve Ashforth, 1992). Aynı zamanda, çalışanlar içinde bulundukları iş ortamları için kendi kimlikleriyle uyumlu olan faaliyetleri benimser ve kendi kimliklerine olumlu etkiler sağlayabilen örgütlerde görev yapmak isterler (Brammer vd., 2007). Bu kavram aynı zamanda çalışanlara kişisel ve sosyal anlamlar da kazandırır (Brammer vd., 2015).

Örgütsel özdeşleşme kavramıla ilgili olarak, yerli yazında da birçok araştırmanın yer aldığı dikkat çekmektedir. Örneğin; İşcan (2006), dönüştürücü/etkileşimci liderlik algısı ve örgütsel özdeşleşme ilişkisinde bireysel farklılıkların rolü üzerine bir araştırma yapmıştır. Akdoğan ve arkadaşları (2016) havacılık sektöründe yaptıkları araştırmada, kurumsal sosyal sorumluluğun örgütsel özdeşleşme üzerindeki olumlu etkilerini incelemiştir. Işık ve Zincirkıran (2017); kurumsal itibar, iş tatmini ve örgütsel özdeşleşmenin üniversite çalışanları üzerindeki etkilerini araştırmıştır. Öz ve Bulutlar'ın (2009) araştırması, banka ve eğitim sektörlerinde kurumsal itibarın örgütsel özdeşleşme üzerindeki etkilerini ortaya koymaktadır. Taşlıyan ve arkadaşları (2016) akademik ve idari personel üzerinde yaptıkları çalışmada, farklılık yönetiminin örgütsel özdeşleşme üzerindeki etkilerini araştırmıştır.

\section{Akış Deneyimi}

Csikzentmihalyi'ye (1990) göre akış deneyimi; bireyin kendisine içsel motivasyon sağlayan, zor olmakla beraber kontrol edebildiği işlerle uğraştığında deneyimlediği benzersiz bir psikolojik durumu ifade eder. Akış; bireyin işine odaklanması, dikkatini toplaması, iş dışındaki hiçbir şeyin önemli olmaması ve bu deneyimin oldukça keyifli olmasından dolayı her durumda yaptığ iş̧e devam etmesidir (Csikzentmihalyi, 1990). Bu durum, 
bireysel olarak yaşandığı gibi, sosyal olarak da yaşanabilmektedir (Walker, 2010). Csikzentmihalyi'ye (1990) göre; yüksek zorluk/yüksek beceri durumunda akış deneyimi yaşanmakta, yüksek zorluk/düşük beceri durumunda kaygılar meydana gelmekte, düşük beceri/düşük zorluk durumunda ilgisizlik oluşmakta, zorluk seviyesinin düşük becerilerin orta düzeyde olmasında ise sıkıntı hissi yaşanabilmektedir.

Akış deneyimi keyifli bir durum olarak tanımlanmakta, bireyi pozitif yönde etkilemekte ve iş performansını önemli ölçüde arttırmaktadır (Nakamura ve Csikzentmihalyi, 2005). Akış deneyiminin temel özellikleri; içsel keyif, zorluk-beceri dengesi, otomatik olarak gerçekleşme, hedeflerin netliği, geribildirim, yapılan işe konsantrasyon, kontrol edebilme hissi, öz bilinç kaybı ve zaman dönüşümüdür (Carr, 2013). Akış deneyimiyle ilgili yazın incelendiğinde; tiyatro (Martin ve Cutler, 2002), müzik (Bakker, 2005), spor (Jackson, 1992; Ada vd., 2012), bilgisayar oyunları (Hsu ve Lu, 2004), internet kullanımı (Rettie, 2001) ve müze ziyaretleri (Aykol ve Aksatan, 2013) gibi bir çok farklı konuda araştırmaların yapıldığı dikkat çekmektedir.

\section{Bilişim Sektöründe Yaşam Doyumu, Örgütsel Özdeşleşme ve Akış Deneyimi Arasındaki İlişkiler}

Bir çalışanın yüksek yaşam doyumu algısına sahip olması, bireyin çalışma ortamında kendisini daha mutlu hissetmesine, hayatı kendi belirlediği ölçütlere göre olumlu bir şekilde algılamasına, kendisi için belirlediği amaçlara ulaşma düzeyinin artmasına ve bunun sonucunda da iş performans1nın yükselmesine neden olmaktadır. Bu nedenle, yüksek yaşam doyumu algısına sahip bir çalışanın kendisi için belirlediği amaçlarını, örgütün amaçlarıyla eşleştirmesi ve bunun sonucunda örgütsel değerleri daha fazla içselleştirerek örgüte sahiplik, bağlılık ve aidiyet değerlerini daha fazla hissetmesi mümkün görünmektedir. Kendini işine verebilen, işini seven ve içe dönük çalışma motivasyonuna sahip olan ve bu şekilde akış deneyimi yaşamaya yatkın olan bireylerin daha yüksek yaşam doyumuna sahip olabilecekleri ve örgütleriyle de daha yüksek seviyede özdeşleşebilecekleri düşünülmektedir. 
Bilişim sektöründe görev yapan çalışanların genel yaşam doyumu algılarının, diğer sektör çalışanlarına kıyasla daha yüksek olabileceği varsayılmaktadır. Bunun nedeni, bilişim sektörünün daha özelleşmiş bilgi ihtiyacı gerektirmesi, entelektüel birikimin daha yüksek olması ihtimali ve işin gerektirdiği yeterliliklerin diğer sektörlere nazaran daha yüksek olması ile açıklanabilir. Bilişim sektörü için gerekli olan kalifiye personel gereksinimi, yüksek deneyim ve özellikle Ar-Ge çalışmaları için gereken ileri seviye eğitim ve bilgi yönetimine yönelik ihtiyaçlar, sektör çalışanlarını yaşam doyumu algısı açısından diğer sektör çalışanlarından farklılaştırmaktadır. Brammer ve arkadaşlarına (2007) göre, birey içinde bulunduğu çalışma ortamında kendi kimliğiyle uyumlu görevleri tercih etmekte ve kendi kimliğine katkı sağlayan örgütlerde görev almak istemektedir. Çalışanın iş ortamında yapmaktan mutluluk duyduğu ve kendi kimliğine katkı sağladığını hissettiği faaliyetleri gerçekleştirmesi durumunda genel yaşam doyumu artabilecek, bunun sonucunda da görev yaptığı örgütü daha fazla sahiplenerek daha yüksek seviyede örgütsel özdeşleşme davranışı gösterebilecektir.

Bilişim sektörü; diğer sektörlerle kıyaslandığında, yüksek seviyede işe odaklanma, yaratıcı davranışlar gösterme ve entelektüel birikimi yaratıcılık faaliyetlerinde kullanabilme becerilerine dönük bir sektör olduğundan, iş yaşamında akış deneyimine yatkınlığın bu sektörde daha yoğun bir şekilde yaşanabileceği ve yaşanan akış deneyiminin de örgütsel özdeşleşme ve yaşam doyumuna olumlu yönde etkilerinin olabileceği varsayılmıştır. Bahsedilen bu varsayımlar çerçevesinde, bilişim sektörü çalışanların genel yaşam doyumu, örgütsel özdeşleşme düzeyleri ve akış deneyimine yatkınlıkları arasındaki ilişkileri temel alan araştırmanın yönetim ve örgüt yazınına katkı sağlayabileceği düşünülmüştür.

\section{Araştırmanın Modeli ve Hipotezler}

Araştırmanın modeli; akış deneyimi, örgütsel özdeşleşme ve yaşam doyumu algısı arasındaki ilişkileri ortaya koymak üzere tasarlanmıştır. Yaşam doyumu algısı ve örgütsel özdeşleşme değişkenlerine yönelik olarak incelenen örgütsel yazın, bu iki değişken arasında olası bir ilişkiye işaret ettiğinden, araştırma modeli bu iki değişken arasındaki ilişkiyi de anlamaya yönelik olarak oluşturulmuştur. Akış deneyiminin alt boyutları olan 
"kendini işe verme", "işi sevme" ve "içe dönük çalışma boyutları, araştırmanın diğer değişkenlerini oluşturmaktadır. Araştırmada, adı geçen alt boyutların örgütsel özdeşleme ve yaşam doyumu değişkenlerine etkilerinin de ortaya konulması amaçlanmıştır. Bahsedilen çerçeveyi esas alan araştırma modeli Şekil 1'de verilmiştir:

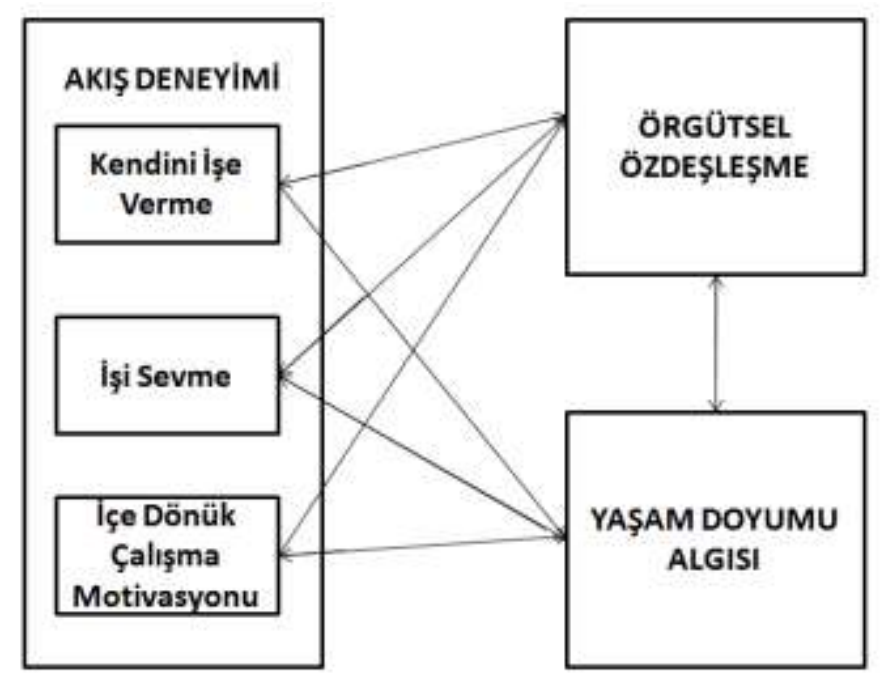

Şekil 1: Araştırma Modeli

Şekil 1'de belirlenen model temel alınarak aşağıda belirtilen hipotezlerin sınanması amaçlanmıştır:

- H1: Çalışanların yaşam doyumu algısı ile örgütsel özdeşleşme düzeyleri arasinda olumlu yönde anlamlı bir ilişki vardır.

- H2: Çalışanlarm yaşam doyumu algısl, örgütsel özdeşleşme düzeylerini olumlu yönde etkiler.

- H3: Çalışanların akış deneyimine yatkınlık düzeyleri (kendini işe verme) ile yaşam doyumu algısı arasında olumlu yönde anlamlı bir ilişki vardır.

- H4: Çalışanların akış deneyimine yatkınlı̆̆ı (kendini işe verme), yaşam doyumu algisini olumlu yönde etkiler.

- H5: Çalışanların akış deneyimine yatkınlık düzeyleri (işi seome) ile yaşam doyumu algısı arasında olumlu yönde anlamlı bir ilişki vardır. 
- H6: Çalı̧anların akış deneyimine yatkınlı̆̆ı (işi seome), yaşam doyumu algısın olumlu yönde etkiler.

- H7: Çalışanların akış deneyimine yatkınlık düzeyleri (içe dönük çalışma motivasyonu) ile yaşam doyumu algısı arasında olumlu yönde anlamlı bir ilişki vardır.

- H8:Çalışanlarm akış deneyimine yatkınlığı (içe dönük çalışma motivasyonu), yaşam doyumu algısını olumlu yönde etkiler.

- H9: Çalışanların akış deneyimine yatkınlık düzeyleri (kendini işe verme) ile örgütsel özdeşleşme düzeyleri arasında olumlu yönde anlamlı bir ilişki vardır.

- H10: Çalışanların akış deneyimine yatkınlığı (kendini işe verme), örgütsel özdeşleşme düzeylerini olumlu yönde etkiler.

- H11: Çalışanların akış deneyimine yatkınlı düzeyleri (işi sevme) ile örgütsel özdeşleşme düzeyleri arasında olumlu yönde anlamlı bir ilişki vardir.

- H12: Çalışanların akış deneyimine yatkınlığı (işi sevme) ile, örgütsel özdeşleşme düzeylerini olumlu yönde etkiler.

- H13: Çalışanların akış deneyimine yatkınlık düzeyleri (içe dönük çalışma motivasyonu) ile örgütsel özdeşleşme düzeyleri arasında olumlu yönde anlamlı bir ilişki vardır.

- H14: Çalışanların akış deneyimine yatkınlığı (içe dönük çalışma motivasyonu), örgütsel özdeşleşme düzeylerini olumlu yönde etkiler.

\section{Araştırma Yöntemi}

\section{Evren ve Örneklem}

Çalışma evreni, Teknopark toplulukları içinde yer alan bilişim firmaları bünyesinde gerçekleştirilen Ar-Ge projelerinde görev yapan bireylerden oluşmaktadır. Bilişim sektöründe görev yapan tüm çalışanlara ulaşmak mümkün olmadığından, araştırma evreni Teknopark toplulukları ile s1nırlandırılmıştır. Araştırmada belirlenen evren üzerinden kolayda örneklem yöntemiyle 214 bilişim sektörü çalışanından anket tekniği ile veri toplanmıştır. 


\section{Araştırmada Kullanılan Ölçekler}

Yaşam Doyumu Ölçeği: Katılımcıların yaşam doyumu algılarını ölçmek amacıyla, Diener ve arkadaşları (1985) tarafindan geliştirilen ve Dağlı ve Baysal (2016) tarafından Türkçe'ye uyarlanan 5 soruluk tek boyutlu ölçek kullanılmıştır. Yaşam doyumu ölçeği, orjinalinde Likert tipinde 7'li derecelendirmeden oluşan bir ölçektir. Bununla birlikte araştırma kapsamındaki veriler Dağlı ve Baysal (2016) tarafından önerilen 5'li Likert ölçeğine göre toplanmıştır. Ölçekteki ifadeler, "İdeallerime yakın bir yaşantım vardır", "Yaşam koşullarım mükemmeldir", "Yaşamımdan memnunum", "Şimdiye kadar yaşamdan istediğim önemli şeylere sahip oldum" ve "Tekrar dünyaya gelsem hayatımdaki hemen hemen hiçbir şeyi değiştirmezdim" şeklindedir. Ölçekteki ifadeler "5-Kesinlikle Katılıyorum, 4-Katılıyorum, 3-Kararsızım, 2-Katılmıyorum, 1-Kesinlikle Katılmıyorum" skalası kullanılarak ölçülmüştür.

Örgütsel Özdeşleşme Ölçeği: Katılımclların örgütsel özdeşleşme düzeylerini ölçmek amacıyla, Mael ve Ashforth (1992) tarafından geliştirilen 6 soruluk tek boyutlu ölçek kullanılmıştır. Ölçekteki bazı ifadeler; "Birisi işyerimi eleştirdiğinde, bunu kişisel bir hakaret olarak görürüm", "Başkalarının işyerim hakkında ne düşündü̈̆̈̈ beni yakından ilgilendirir", "İşyerim hakkında konuşulduğunda genelde onlar yerine biz derim", "İşyerimin başarıları benim başarılarımdır", "Birisi işyerimi övdüğ̈̈nde bunu kişisel bir iltifat olarak görürüm” ve "Eğer işyerim herhangi bir nedenle eleştirmişse bundan utanç duyarım" şeklindedir. Ölçekteki ifadeler "5-Kesinlikle Katılıyorum, 4-Katılıyorum, 3Kararsızım, 2-Katılmıyorum, 1-Kesinlikle Katılmıyorum" skalası kullanılarak 5'li Likert ölçeğine göre ölçülmüştür.

Akış Deneyimi Ölçeği: Akış deneyimi ve alt boyutlarını ölçmek amacıyla; Bakker (2008) tarafından geliştirilen WOLF (The Work Related Flow Inventory) ölçeği kullanılmıştır. Ölçek toplamda 13 madde ve 3 alt boyuttan (kendini işe verme, işi sevme ve işe dönük çalışma motivasyonu) oluşmaktadır. Ölçekteki ifadeler "7-Her Zaman, 1-Hiç" skalası kullanılarak 7'li Likert ölçegine göre ölçülmüştür. 


\section{Bulgular}

\section{Demografik Özellikler}

Katılımcıların yaş ortalamaları 25-34 aralığında $(\mathrm{m}=2,322$; $\mathrm{ss}=0,8633)$, toplam çalışma süresi ortalamaları 6-10 yıl ( $\mathrm{m}=2,341$; ss: 1,3323$)$ ve eğitim durumları ortalama olarak lisans seviyesindedir $(\mathrm{m}=3,313$, $\mathrm{ss}=0,7187)$. Kat1lımcların \% 35'i (N=75) kadın olup, \% 65'i (N=139) erkektir. Evli katılımcıların oranı \% $50(\mathrm{~N}=107)$ ve bekâr katılımciların oranı da \% 50'dir $(\mathrm{N}=107)$.

Tablo 1: Demografik Özellikler

\begin{tabular}{|c|c|c|c|}
\hline Faktör & & n & $\%$ \\
\hline \multirow{2}{*}{ Cinsiyet } & Erkek & 139 & 65 \\
\hline & Kadın & 75 & 35 \\
\hline \multirow{2}{*}{ Medeni Durum } & Evli & 107 & 50 \\
\hline & Bekar & 107 & 50 \\
\hline \multirow{5}{*}{ Yaş } & 18-24 Yaş Arası & 34 & 15,9 \\
\hline & 25-34 Yaş Arası & 98 & 45,8 \\
\hline & 35-44 Yaş Arası & 62 & 29 \\
\hline & 45-54 Yaş Arası & 19 & 8,9 \\
\hline & 55 ve Üstü & 1 & 0,5 \\
\hline \multirow{5}{*}{ Toplam Çalışma Süresi } & $0-5 Y_{11}$ & 82 & 38,3 \\
\hline & $6-10 Y_{11}$ & 42 & 18,6 \\
\hline & 11-15 Y 11 & 43 & 20,1 \\
\hline & $16-20 Y_{11}$ & 29 & 13,6 \\
\hline & 20 Y1l Üzeri & 18 & 8,4 \\
\hline \multirow{5}{*}{ Eğitim Durumu } & Lise & 4 & 1,9 \\
\hline & Ön Lisans & 8 & 3,7 \\
\hline & Lisans & 131 & 61,2 \\
\hline & Y.Lisans & 59 & 27,6 \\
\hline & Doktora & 12 & 5,6 \\
\hline
\end{tabular}




\section{Ölçeklerin Güvenilirliği ve Geçerliliği}

İstatistiksel programlar aracılığıyla yapılan güvenilirlik analizleri sonucunda; toplam 5 maddeden oluşan yaşam doyumu ölçeğine ait Cronbach Alpha değerinin < 0,70 olduğu görülmüştür. Bu nedenle ölçekteki 5 . madde olan "Tekrar dünyaya gelsem hayatımdaki hemen hemen hiçbir şeyi değiştirmezdim" sorusu çıarılarak güvenilirlik testleri tekrar edilmiştir. Bu şekilde gerçekleştirilen testler sonucunda Cronbach Alpha değerinin 0,847 olduğu görülmüş ve araştırmaya ölçekteki 4 soru dikkate alınarak devam edilmiştir.

6 maddeden oluşan örgütsel özdeşleşme ölçeğine ait Cronbach Alpha değerinin 0,798 olduğu görülmüştür. Kullanılan ölçeğin güvenilirlik değeri > 0,70 olduğundan ilgili ölçeğin araştırma kapsamında kullanımının uygun olduğu düşünülmüştür.

13 maddeden oluşan akış deneyimi ölçeği için gerçekleştirilen güvenilirlik analizleri sonucunda, ölçeğin tek boyut altındaki Cronbach Alpha değerinin 0,910 olduğu görülmüştür. Akış deneyimi ölçeğinin 4 maddeden oluşan "kendini işe verme" boyutu için Cronbach Alfa değerinin 0,851, 4 maddeden oluşan "işi sevme" alt boyutunun Cronbach Alfa değerinin 0,943 ve 5 maddeden oluşan "içe dönük çalışma motivasyonu" alt boyutunun Cronbach Alfa değerinin ise 0,807 olduğu tespit edilmiştir.

Kullanılan ölçeklerin geçerliliğini test etmek için, yaşam doyumu, örgütsel özdeşleşme ve akış deneyimi ölçeklerine doğrulayıcı faktör analizleri (DFA) uygulanmıştır. Yaşam doyumu ölçeğinin DFA sonuçları Tablo 1'de verilmiştir:

Tablo 2: Yaşam Doyumu Ölçeğinin DFA Geçerlilik Sonuçları

\begin{tabular}{lllllll}
\hline Model & $\Delta \chi^{2}$ & $\Delta \chi^{2} / \mathbf{s d}$ & RMSEA & CFI & GFI & RMR \\
\hline Birinci Düzey Tek Faktörlü & 0,082 & 0,082 &, 000 & 1,000 & 1,000 &, 02 \\
\hline
\end{tabular}

RMSEA = Root Mean Square Error of Approximation; GFI= Goodness of Fit Index, CFI= Comparative Fit Index; RMR= Root Mean Square Residual. $(p<.001)$.

Yaşam doyumu ölçeği birinci düzey tek faktörlü modelde, modifikasyon indislerde e3-e4 kovaryansları arasında yapılan iyileştirmelerle birlikte en iyi uyumu göstermiştir. $\Delta \chi^{2} / \mathrm{sd}=0,082$ ( $\leq 3$ mükemmel uyum), RMSA=0,000 ( $\leq$ 0,05 mükemmel uyum), CFI=1,000 ( $\geq 0,90$ mükemmel 
uyum), GFI=1,000 ( $\geq 0,90$ mükemmel uyum), $R M R=0,02$ ( $\leq 0,05$ mükemmel uyum).

Bu bulgular doğrultusunda, yaşam doyumu ölçeği için Tablo 2'de verilen birinci düzey tek faktörlü modelin uyum iyiliği açısından araştırma kapsamında geçerli olduğuna karar verilmiştir.

Tablo 3: Örgütsel Özdeşleşme Ölçeğinin DFA Sonuçları

\begin{tabular}{lllllll}
\hline Model & $\Delta \boldsymbol{\chi}^{2}$ & $\Delta \boldsymbol{\chi}^{2} / \mathbf{s d}$ & RMSEA & CFI & GFI & RMR \\
\hline Birinci Düzey Tek Faktörlü & 13,106 & 1,638 &, 055 &, 986 &, 981 &, 034 \\
\hline
\end{tabular}

RMSEA= Root Mean Square Error of Approximation; GFI= Goodness of Fit Index, CFI= Comparative Fit Index; RMR= Root Mean Square Residual. $(p<.001)$.

Tablo 3'de verilen DFA sonuçlarından görüldüğü üzere, örgütsel özdeşleşme ölçeği birinci düzey tek faktörlü modelde modifikasyon indislerde (e3-e4 arasında) yapılan iyileştirmelerle en iyi uyumu göstermiştir. $\Delta \chi^{2} / \mathrm{sd}=1,638$ ( $\leq 3$ mükemmel uyum), RMSA=0,055 (0,06-0,08 arası kabul edilebilir uyum), $C F I=0,986$ ( $\geq 0,90$ mükemmel uyum), $\mathrm{GFI}=0,981(\geq 0,90$ mükemmel uyum), $R M R=0,034$ ( $\leq 0,05$ mükemmel uyum).

Bu bulgular doğrultusunda, örgütsel özdeşleşme ölçeği için Tablo 3' de verilen birinci düzey tek faktörlü modelin uyum iyiliği açısından araştırma kapsamında geçerli olduğuna karar verilmiştir.

Tablo 4: Akış Deneyimi Ölçeğinin DFA Sonuçları

\begin{tabular}{lcccccc}
\hline Model & $\Delta \chi^{2}$ & $\Delta \chi^{2} / \mathbf{s d}$ & RMSEA & CFI & GFI & RMR \\
\hline $\begin{array}{l}\text { Birinci Düzey Tek } \\
\text { Faktörlü }\end{array}$ & 498,800 & 7,674 & 0,177 & 0,760 & 0,687 & 1,216 \\
\hline $\begin{array}{l}\text { Birinci Düzey Çok } \\
\text { Faktörlü }\end{array}$ & 140,970 & 2,274 & 0,077 & 0,956 & 0,907 & 0,048 \\
\hline
\end{tabular}

RMSEA= Root Mean Square Error of Approximation; GFI= Goodness of Fit Index, CFI= Comparative Fit Index; RMR= Root Mean Square Residual. $(p<.001)$.

Tablo 4'de verilen DFA sonuçlarında göre, akış deneyimi ölçeği birinci düzey çok faktörlü modelde en iyi uyumu göstermiştir. $\Delta \chi^{2} / \mathrm{sd}=2,274(\leq 3$ mükemmel uyum), RMSA=0,077 (0,06-0,08 arası kabul edilebilir uyum), $\mathrm{CFI}=0,956$ ( $\geq 0,90$ mükemmel uyum), $\mathrm{GFI}=0,907$ ( $\geq 0,90$ mükemmel uyum), $\mathrm{RMR}=0,048(\leq 0,05$ mükemmel uyum). 
Bu bulgular doğrultusunda, akış deneyimi ölçeği için Tablo 4'de verilen birinci düzey çok faktörlü modelin uyum iyiliği açısından araştırma için geçerli olduğuna karar verilmiştir

\section{Korelasyon Analizleri}

Yaşam doyumu, örgütsel özdeşleşme ve akış deneyiminin alt boyutlarını oluşturan değişkenler arasındaki korelasyon ilişkilerini gösteren bulgular Tablo 5'de özetlenmiştir:

Tablo 5: Değişkenler Arasındaki Korelasyon İlişkileri

\begin{tabular}{llllllll}
\hline Değişkenler & $\mathbf{M}$ & SD & $\mathbf{1}$ & $\mathbf{2}$ & $\mathbf{3}$ & $\mathbf{4}$ & $\mathbf{5}$ \\
\hline 1.Yaşam Doyumu & 3,15 & 1,11 & 1 & & & & \\
2.Örgütsel Özdeşleşme & 3,47 &, 73 &, 046 & 1 & & \\
3. AD1-Kendini İşe Verme & 3,31 &, 78 &, 068 &, $346^{*}$ & 1 & & \\
4. AD2-İşi Sevme & 3,59 & 0,87 &, $242^{* *}$ & $, 407^{* *}, 470^{* *} 1$ & \\
5.AD3-İçe Dön. Çal. M. & 3,16 & 0,86 & $, 178^{* *}, 432^{* *}, 505^{* *}, 701^{* *}$ & 1 \\
\hline
\end{tabular}

$N=214 ; M=$ ortalama; $S D=$ standart sapma; ${ }^{*} p \leq 0,05 ;{ }^{* *} p \leq 0,01$ (AD: Akış Den.)

Tablo 5 incelendiğinde, yaşam doyumu algısı ve örgütsel özdeşleşme düzeyi arasında herhangi bir korelasyon ilişkisinin $(r=0.046, p>0,05)$ bulunmadığı görülmektedir.

İş yaşamında akış deneyiminin tek boyutta ele alınması durumunda, bu değişkenin yaşam doyumu algısıyla olumlu yönde ve anlamlı korelasyon ilişkilerinin bulunduğu $(r=0,197, p<0,01)$ görülmüştür. Böyle olmakla beraber, bireyin kendisi işe vermesi ile yaşam doyumu algısı arasında anlamlı bir korelasyon ilişkisi $(r=0,068, p>0,05)$ görülememiştir. Fakat bireyin işini sevmesinin yaşam doyumuyla olumlu yönde ve anlamlı bir ilişkisi $(\mathrm{r}=0,242, \mathrm{p}<0,01)$ bulunaktadır. Aynı zamanda içe dönük çalışma motivasyonu ile yaşam doyumu arasında da anlamlı ve olumlu yönde bir korelasyon $(\mathrm{r}=0,178, \mathrm{p}<0,01)$ vardır.

İş yaşamında akış deneyiminin tek boyutta ele alınması durumunda, çalışanın akış deneyimine yatkınlığı ve örgütüyle özdeşlemesi arasında $(\mathrm{r}=0,472, \mathrm{p}<0,01)$ anlamlı bir korelasyon mevcuttur. Çalışan örgütüyle özdeşleşebildiğinde; kendisini işine daha fazla verebilmekte $(\mathrm{r}=0,346$, $\mathrm{p}<0,01)$, işini daha fazla sevmekte $(\mathrm{r}=0,407, \mathrm{p}<0,01)$ ve işe dönük çalışma motivasyonu da $((\mathrm{r}=0,505, \mathrm{p}<0,01))$ daha yüksek olabilmektedir. 


\section{Yapısal Eşitlik Modeli}

Araştırma kapsamında belirlenen hipotezlerin sınanması için yapısal eşitlik modellemesi analizi yapılmıştır. Bu amaçla; akış deneyiminin alt boyutları (kendini işe verme, işi sevme ve işe dönük çalışma motivasyonu), yaşam doyumu ve örgütsel özdeşleşme arasındaki yapısal ilişkiye yönelik bir model oluşturulmuştur.

Yapısal eşitlik modeli çalışması öncesinde gerçekleştirilen korelasyon analizleri, yaşam doyumu ile örgütsel özdeşleşme arasında herhangi bir korelasyon ilişkisi göstermediğinden, kurulan yapısal eşitlik modelinde de bu ilişki kurgulanmamıştır. Bununla birlikte, çalışanın kendini işe vermesiyle yaşam doyumu arasında da herhangi bir korelasyon ilişkisi bulunmadığından, bu iki değişken arasında da bir bağlantı oluşturulmamıştır. Bilişim sektöründe çalışanların yaşam doyumuna yönelik algılarının örgütsel özdeşleme düzeyleri ve akış deneyiminin alt boyutlarıyla ilişkilerini ortaya koymak için yapısal eşitlik modellemesi yaklaşımıyla kurulan yapısal regresyon modeli Şekil 2' de verilmiştir. Yapısal regresyon modeli (Şekil 2) kapsamında elde edilen uyum iyiliği değerleri Tablo 6' de verilmiştir.

Tablo 6: Uyum İyiliği Değerleri

\begin{tabular}{lcccccc}
\hline Model & $\Delta \chi^{2}$ & $\Delta \chi^{2} /$ sd & RMSEA & CFI & GFI & RMR \\
\hline $\begin{array}{l}\text { Yapisal Regresyon } \\
\text { Modeli }\end{array}$ & 436,953 & 1,942 & 0,067 & 0,921 & 0,842 & 0,0833 \\
\hline
\end{tabular}

Tablo 6' daki uyum iyiliği değerleri incelendiğinde $\Delta \chi^{2} / \mathrm{sd}=1,942(\leq 3 \mathrm{mü}-$ kemmel uyum), RMSA=0,067 (0,06-0,10 arasi kabul edilebilir uyum), CFI $=0,921$ ( $\geq 0,90$ mükemmel uyum), GFI=0,842 (0,89-0,85 arası kabul edilebilir uyum), $\mathrm{RMR}=0,0833$ (0,06-0,10 arası kabul edilebilir uyum) sonuçlarının uygun olduğu görülmüştür. 


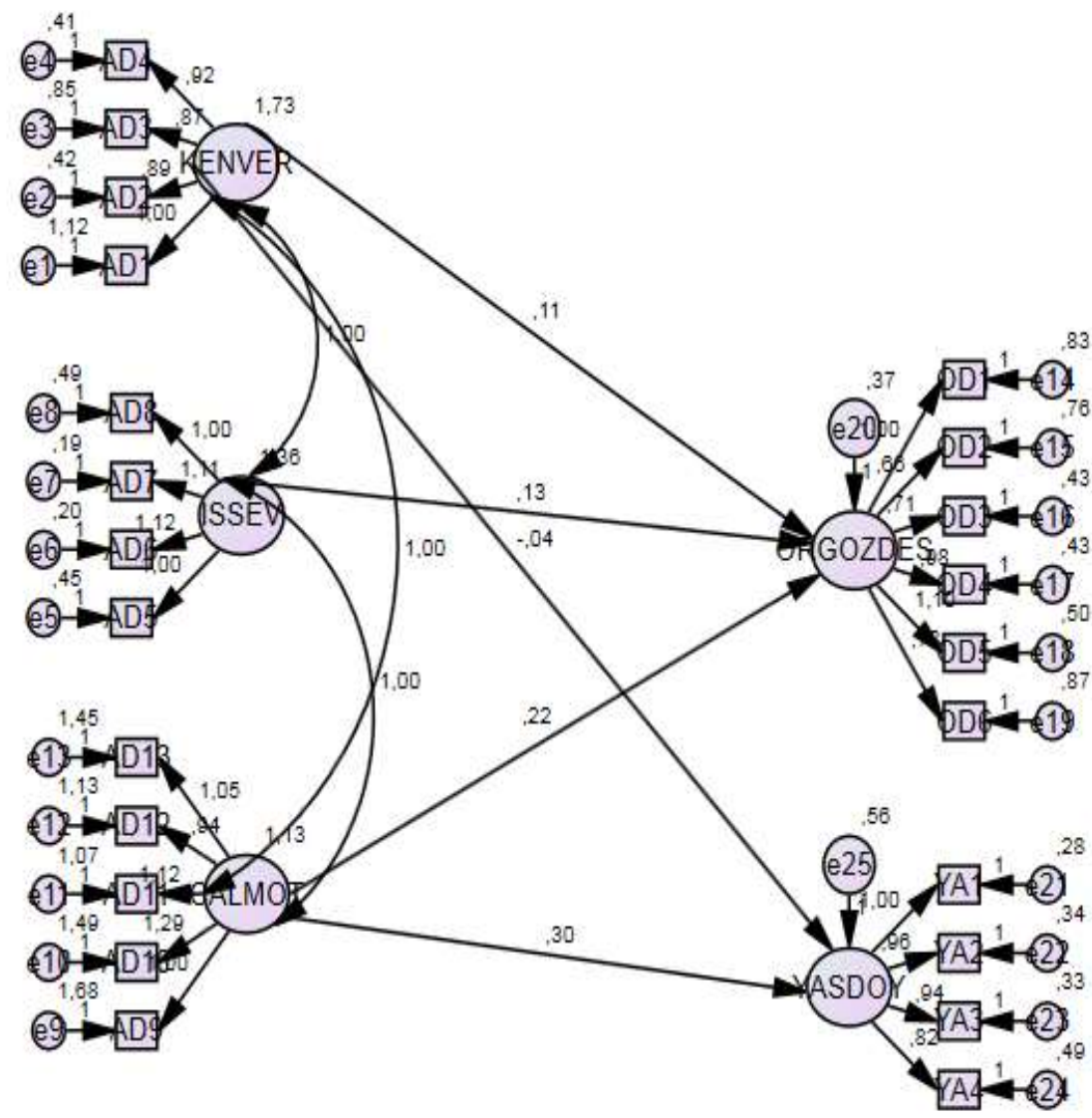

Şekil 2: Yapısal Eşitlik Modeli

(KENVER: Kendini İşe Verme, ISSEV: İşi Sevme, CALMOT: İçe Dönük Çalışma Motivasyonu, ORGOZDES: Örgütsel Özdeşleşme, YASDOY: Yaşam Doyumu)

Kurulan modele göre; akış deneyimine yatkınlığın bir alt boyutu olan kendini işe verme $(\beta=0,11 p<0,05)$ boyutunun örgütsel özdeşleşmeye anlamlı ve pozitif yönde bir etkisi bulunmaktadır. Yani, çalışanın kendini daha fazla işe vermesinin örgütsel özdeşleşmeye olumlu yönde bir etkisi bulunmaktadır. Aynı zamanda, bireyin işini sevmesinin de örgütsel özdeşleşmeye olumlu yönde etkisi olduğu $(\beta=0,13 p<0,05)$ görülmüştür. İçe 
dönük çalışma motivasyonu da örgütsel özdeşleşmeyi olumlu yönde ( $\beta=$ $0,22 \mathrm{p}<0,05)$ etki etmektedir. Bununla birlikte, bireyin içe dönük çalışma motivasyonu, yaşam doyumu algısını olumlu yönde $(\beta=0,30 p<0,05)$ etkileyebilmektedir. Kendini işe vermenin yaşam doyumu üzerinde negatif yönde ve oldukça düşük şiddette bir etkisi olduğu $(\beta=-0,04, p<0,05)$ görülürken, işi sevmenin yaşam doyumu algısıyla herhangi bir ilişkisi görülememiştir. Yapısal regresyon analizi sonuçları genel olarak değerlendirildiğinde, akış deneyimi alt boyutlarının örgütsel özdeşlemeye olumlu yönde etkileri söz konusu iken, yaşam doyumuna etkileri daha çok içe dönük çalışma motivasyonu ile sınırlı kalmaktadır.

\section{Sonuç ve Öneriler}

Araştırmanın sonuçları, bilişim sektörü çalışanlarının yaşam doyumu algıları ile örgütsel özdeşleşme düzeyleri arasında herhangi bir ilişkinin olmadığını göstermiştir. Bu nedenle, çalışanların yaşam doyumu algısı ile örgütsel özdeşleşme düzeyleri arasında olumlu yönde anlamlı bir ilişki olduğuna yönelik hipotez (H1) kabul edilmemiştir. Yaşam doyumu algısı ile örgütsel özdeşleşme arasında anlamlı bir korelasyon ilişkisi olmadığından, çalışanların yaşam doyumu algısının, örgütsel özdeşleşme düzeylerini etkilediğine yönelik hipotez de (H2) kabul edilmemiştir. Bu sonucun, çalışanların genel yaşam doyumu ve iş doyumu algıları arasındaki temel farklılıklardan kaynaklandığı düşünülmektedir. Elde edilen bu sonuç, yaşam doyumunun iş doyumuyla bir arada ele alınmasını gerektiğini söyleyen birçok araştırmayı belirgin bir şekilde doğrulamaktadır. Örneğin Dikmen (1995), iş ve yaşam arasında yoğun bir şekilde yaşanan iç içe geçmişlik durumunu ortaya koyarken, yaşam doyumunun iş doyumuyla bir arada ele alınmasını gerektiğini açık bir şekilde belirtmiştir. Braysfield ve arkadaşları'nın (1957) ifade ettikleri şekilde iş yaşamı bireyin iş dışındaki genel yaşamını yoğun bir şekilde etkilemesine rağmen, genel yaşam doyumu iş yaşamıyla ilgili doyumdan farklılıklar göstermekte ve birey genel yaşam doyumunu yüksek düzeylerde hissetmesine rağmen, bu hislerini örgütsel yaşamla birebir ilişkilendiremeyebilmektedir. Çalışmadan elde edilen bu sonuç, genel yaşam doyumu ve iş yaşamına yönelik doyum arasındaki farklılıkları ifade eden örgütsel yazını açık bir şekilde doğrulamaktadır. 
Araştırmadan elde edilen sonuçlar, çalışanın kendini işe vermesi ile yaşam doyumu arasındaki olası bir ilişkiyi vurgulamaktadır. Çalışanların kendini işe vermesi ile yaşam doyumu algısı arasında olumlu yönde anlamlı bir ilişkinin olduğuna ve kendini işe vermenin yaşam doyumunu olumlu yönde etkileyebileceğine yönelik hipotezler (H3 ve H4) kabul edilmiştir. Elde edilen bu sonuç, bilişim sektörünün gerektirdiği yoğunlaşma, dikkat ve işe odaklanma ihtiyaçlarının önemine dikkat çekmektedir. İşine daha fazla odaklanan bireyin yaşam doyumuna yönelik algılarının yükselmesi mantıklı bir durum olarak görünmektedir.

Bulgular, yapılan işi sevme ile yaşam doyumu hissetme arasında herhangi bir korelasyon ilişkisinin olmadığını göstermiştir. Bu durum, sevilen bir işte çalışmanın ancak iş doyumuyla ilişkili olabileceğini gündeme getirmektedir. Bireyin işini sevmesi durumunda hissedebileceği duygu, yaşam doyumundan ziyade iş doyumuna yönelik bir duygu olmaktadır. Elde edilen istatistiksel sonuçlar ve yapılan açıklamalar neticesinde, çalışmanın 5. ve 6. hipotezleri de reddedilmiştir.

İçe dönük çalışma motivasyonuna sahip olan bireylerin, daha yüksek yaşam doyumu algısına sahip olabilecekleri açıtır. Bilişim sektörünün bireysel çalışmaya yönelik bir yapısının olması ve kodlama faaliyetlerinin bireysel üretime yakın bir yaklaşım taşıması, içe dönük çalışma motivasyonunun bireyin yaşam doyumuna katkı sağlayabileceğini düşündürmektedir. Elde edilen istatistiksel bulgular da, bu düşünceyi doğrulamaktadır. Çalışanların içe dönük çalışma motivasyonuna sahip olmaları ile yaşam doyumu algıları arasındaki olumlu yöndeki anlamlı ilişkinin varlığını ifade eden hipotez (H7) ile içe dönük çalışma motivasyonunun yaşam doyumunu olumlu yönde etkilediğini ifade eden hipotez (H8) kabul edilmiştir.

Araştırmanın sonuçları; kendini işine verebilen, işini seven ve içe dönük çalışma motivasyonu gösterebilen çalışanların, aynı zamanda örgütsel özdeşleşme davranışı da gösterdiklerini ortaya koymaktadır. Bu kapsamda; iş yaşamında akış deneyimine yatkınlığın alt boyutları olan kendini işe verme, işi sevme ve içe dönük çalışma motivasyonunun örgütsel özdeşleşmeyle ilişkisini ve etkisini ortaya koyan hipotezler (H9,H10,$\mathrm{H} 11, \mathrm{H} 12, \mathrm{H} 13$ ve H14) de kabul edilmiştir. 
Yapılan bu araştırmanın; bilişim sektöründe görev yapan çalışanların örgütsel davranış biçimlerinin anlaşılmasına, bu konuda ortaya konulabilecek yönetsel stratejilerin belirlenmesine, sektör çalışanlarının yaşam doyumu algılarının, örgütsel özdeşleşmeye ilişkin davranışlarının ve akış deneyimi yatkınlıklarının belirlenmesine ışık tutması açısından bilişim sektörü yöneticilerine ve örgütsel yazına farklı açlardan faydalar sağlayabileceği düşünülmektedir. 


\title{
EXTENDED ABSTRACT
}

\section{The Relationships among Perceptions of Life Satisfaction, Organizational Identification Levels and Flow Experience of Employees: the Case of Information Technology (IT) Sector}

\author{
Cemalettin Öcal Fidanboy
}

Fidanboy Consulting

Developments in today's business world cause the individual to spend a large part of his/her general life in the work environment. While the individual lives his/her general life, he/she can find himself/herself in an intensive work environment and may have significant problems in actively focusing on work and absorbing himself/herself into work. Considering today's technological possibilities, it is impossible to think of general life and business life as isolated concepts from each other. This intertwining between general life and business life also raises the possibility that an employee who is happy with the general life and evaluates the quality of life positively can adapt to his organization and feel himself as a part of the organization. From this point of view, the possible relationships between the general life satisfaction of the employee, his/her identification with his/her organization and finding himself /herself prone to flow experience are important facts that need to be evaluated in terms of management.

The satisfaction and experience gained from the work of the employee affect the general life outside the work intensively (Brayfield vd., 1957). In other words, working life is a concept that has a significant effect on nonworking life. Satisfaction obtained from business life has a great contribution to the formation of life satisfaction for the individual. At the same time, job satisfaction is a phenomenon that can be evaluated as a subfield 
of general life satisfaction (Keser, 2005). Experience in the work environment may affect the general life of the individual positively or negatively. Similarly, general life experience may have positive or negative effects on business life. It is also possible that the positive experience gained from general life may have impact on the business life. As a result, it is possible for the individual to identify himself/herself with the organization in which he/she works; to feel himself/herself as a part of the organization and to exhibit a higher level of organizational identification behavior. According to Mael and Ashforth (1992), organizational identification is defined as the individual's objectives being matched with the aims of the organization and that the individual feels as part of the organization. Individuals who are identified with their organization may perceive the success or failure of their organizations as their own success or failure (Ashforth and Mael, 1989).

Owning to the opportunities brought by technology; when an employee suddenly finds himself/herself in an active work environment while living his/her general life, it requires a strong focus and the ability to get absorbed. This strong focusing ability is defined in the organizational literature as being prone to flow experience. Csikzentmihalyi (1990) refers to a unique psychological state that provides intrinsic motivation, experienced in difficult but controllable situations. This psychological state which is called flow experience in business life, may have some relations with life satisfaction and identification of the individual with the organization. Being prone to flow experience is defined as an enjoyable experience and has effects on the individual positively and can provide important advantages to business performance (Nakamura and Csikzentmihalyi, 2005). It is very important for an individual to exhibit a behavior that is prone to experiencing flow experience in business life in terms of contributing to organizational identification and perception of life satisfaction. The need for intrinsic motivation and focus, which has become more and more important with today's technological developments, can become an important recipe for reducing the problems of intertwining between life satisfaction and job satisfaction.

In this study, it is assumed that there are some basic relationships between employee's perception of life satisfaction, organizational identification level and being prone to flow experience. Data where obtained from 
IT sector individuals. Hypotheses were formed regarding the research model. The hypotheses were tested on the basis of IT sector data. The results of the research are discussed with regards to the dynamics of the IT sector.

The fact that the employee has a high perception of life satisfaction causes the individual to feel happier in the work environment. Also it causes to perceive life in a positive way and it causes to increase the level of achievement of the goals to increase the business performance. At the same time, the individual feels the values of identification, loyalty and belonging to the organization more by internalizing the organizational values more. It is thought that individuals who can absorb themselves into their work love their work and have the intrinsic motivation to work. Employees who are prone to flow experience can have higher life satisfaction and can show higher organizational identification. It is assumed that the perception of general life satisfaction of employees working in the IT sector may be higher than that of other sector employees. The reason for this can be explained by the fact that the IT sector requires more specialized information needs; the possibility of intellectual accumulation is higher and the qualifications required by the job are higher than other sectors. The need for qualified personnel, high experience and the need for advanced training and knowledge management especially for $R \& D$ activities differentiate this sector's employees from other sector employees in terms of perception of life satisfaction. According to Brammer et al. (2007), the individual prefers tasks that are compatible with his / her own identity and wants to work in organizations that contribute to his/her own identity. If the employee involves in the activities that he / she is happy to do in the work environment and feels that he/she contributes to his/her identity, the overall life satisfaction may increase, therefore, he/she can adapt to the organization he/she is working for more and show a higher level of organizational identification behavior. Compared to other sectors, the IT sector is focused on the ability to focus on a high level of work, to show creative behavior and to use intellectual knowledge in creativity activities. It is assumed that this sector's tendency to flow experience in business life can be more intensive in this sector and that flow experience can have positive effects on organizational identification and life satisfaction. It is 
thought that the research which is based on the relationships between general life satisfaction, organizational identification levels and tendency to flow experience of the IT sector employees can contribute to management and organizational literature.

The results of the study showed that there is no relationship between life satisfaction perceptions and organizational identification levels of IT employees. Hence, the hypothesis which includes the positive relationship between employees' perception of life satisfaction and organizational identification levels was not accepted. Since there is no significant correlation between the perception of life satisfaction and organizational identification, the hypothesis pointing at the perception of life satisfaction of the employees affecting the levels of organizational identification was rejected. This result might be due to the fundamental differences between general life satisfaction and job satisfaction perceptions of employees. This result clearly confirms many studies which mentioned that life satisfaction should be handled with job satisfaction. Braysfield et al. (1957) stated that although working life intensively affects the general life of the individual outside of work, general life satisfaction differs from job-related satisfaction and although the individual feels general life satisfaction at high levels, he / she may not be able to relate this feeling to organizational life. This is in accordance with the organizational literature expressing the differences between general life satisfaction and job satisfaction. The results of the study imply a possible relationship between employee self-employment and life satisfaction. Hypotheses were accepted that there is a positive meaningful relationship between self-employment and perception of life satisfaction and that self-employment may affect life satisfaction positively. This result draws attention to the importance of the concentration, attention and focus needs of the IT sector. It seems logical that an individual who focuses more on his/her job increases his/her perception of life satisfaction.

The findings showed that there was no correlation between loving the job and feeling life satisfaction. This suggests that working in a favorable job can only be related to job satisfaction. The feeling that an individual may feel if he/she likes his/her job is a feeling of job satisfaction rather than life satisfaction. 
It is clear that individuals with the intrinsic motivation may have a higher perception of life satisfaction. The fact that the IT sector has a structure for individual work and that the coding activities take a close approach to individual production suggests that intrinsic motivation can contribute to the life satisfaction of the individual. The findings show that employees, who are able to get absorbed into their jobs, love their jobs and show intrinsic motivation also exhibit organizational identification behavior.

This research can provide significant directions to IT managers, IT employees and organizational literature from different perspectives in many respects. The findings obtained from the study will contribute to the understanding of the organizational behavior of the employees working in the IT sector and help to determine the managerial strategies within the scope of IT management.

\section{Kaynakça / References}

Ada, E. N. D., Aşcı, F. H., Çetinkalp, F. Z. K. ve Altıparmak, M. E. (2012). Sürekli optimal performans duygu durum-2 (SOPDD-2) ölçeğinin beden eğitimi dersi için değerlendirilmesi. Spor Bilimleri Dergisi, 23(2), 43-49.

Akdoğan, A. A., Arslan, A. ve Demirtaş, Ö. (2016). A strategic influence of corporate social responsibility on meaningful work and organizational identification, via perceptions of ethical leadership. Procedia-Social and Behavioral Sciences, 235, 259-268.

Ashforth, B. E. ve Mael, F. (1989). Social identity theory and the organization. Academy of Management Review, 14(1), 20-39.

Aykol, B. ve Aksatan, M. (2013). Akış teorisinin müze ziyaretlerine uygulanabilirliğine dair kavramsal bir model ve araştırma önerileri. $P a-$ zarlama ve Pazarlama Araştırmaları Dergisi, 6(12), 69-90.

Bakker, A.B. (2005). Flow among music teachers and their students: The crossover peak experiences. Journal of Vocational Behavior, 66, 26-44.

Bakker, A. B. (2008). The work-related flow inventory: Construction and initial validation of the WOLF. Journal of Vocational Behavior, 72(3), 400-414. 
Brammer, S., He, H. ve Mellahi, K. (2015). Corporate social responsibility, employee organizational identification and creative effort: the moderating impact of corporate ability. Group $\mathcal{E}$ Organization Management, 40(3), 323-352.

Brammer, S., Millington, A. ve Rayton, B. (2007). The contribution of corporate social responsibility to organizational commitment. The International Journal Of Human Resource Management, 18(10), 17011719.

Brayfield, A. H., Wells, R. V. ve Strate, M. W. (1957). Interrelationships among measures of job satisfaction and general satisfaction. Journal of Applied Psychology, 41(4), 201.

Carr, A. (2013). Positive psychology: The science of happiness and human strengths. Routledge.

Csikszentmihalyi, M. (1990). Flow: The psychology of optimal experience. Harper Collins, Modern Classics.

Dağl1, A. ve Baysal, N. (2016). Yaşam doyumu ölçeğinin Türkçe'ye uyarlanması: geçerlik ve güvenirlik çalısması. Elektronik Sosyal Bilimler Dergisi, 15(59), 1250-1262.

Diener E. D., Emmons, R. A., Larsen, R. J. ve Griffin, S. (1985). The satisfaction with life scale. Journal of Personality Assessment, 49(1), 71-75.

Dikmen, A. A. (1995). İş doyumu ve yaşam doyumu ilişkisi. Ankara Üniversitesi SBF Dergisi, 50 (03), 115-140.

Dockery, A. M. (2003). Happiness, life satisfaction and the role of work: evidence from two Australian surveys. Full Employment Imperative, 77.

Dost, M. T. (2007). Üniversite öğrencilerinin yaşam doyumunun bazı değişkenlere göre incelenmesi. Pamukkale Üniversitesi Eğitim Fakültesi Dergisi, 22(22), 132-143.

Dutton, J. E., Dukerich, J. M. ve Harquail, C. V. (1994). Organizational images and member identification. Administrative Science Quarterly, 239-263.

Edwards, M. R. (2005). Organizational identification: A conceptual and operational review. International Journal Of Management Reviews, 7(4), 207-230. 
Edwards, M. R. ve Peccei, R. (2007). Organizational identification: development and testing of a conceptually grounded measure. European Journal of Work And Organizational Psychology, 16(1), 25-57.

Emmons, R. A. ve Diener, E. (1985). Personality correlates of subjective well-being. Personality And Social Psychology Bulletin, 11(1), 89-97.

Hsu, C. L. ve Lu, H. P. (2004). Why do people play on-line games? An extended TAM with social influences and flow experience. Information \& Management, 41(7), 853-868.

Işık, M ve Zincirkıran, M. (2017). Kurumsal itibar, iş tatmini ve örgütsel özdeşleşme kavramlarının demografik değişkenler ıle incelenmesi: Doğu Anadolu Bölgesi'ndeki üniversitelerde bir araştırma. Finans Politik \& Ekonomik Yorumlar, 54(623), 21.

İşcan, Ö.F. (2006). Dönüştürücü/etkileşimci liderlik algısı ve örgütsel özdeşleşme ilişkisinde bireysel farklılıkların rolü. Akdeniz İ.̇.B.F., 11, 160- 177.

Jackson, S. A. (1992). Athletes in flow: A qualitative investigation of flow states in elite figure skaters. Journal of Applied Sport Psychology, 4(2), 161-180.

Keser, A. (2005). Çalışma yaşamı ile yaşam doyumu ilişkisine teorik bakış. İstanbul Üniversitesi İktisat Fakültesi Mecmuası, 55(1), 897-913.

Mael, F. ve Ashforth, B. E. (1992). Alumni and their alma mater: a partial test of the reformulated model of organizational identification. Journal of Organizational Behavior, 13(2), 103-123.

Martin, J. J. ve Cutler, K. (2002). An exploratory study of flow and motivation in theater actors. Journal of Applied Sport Psychology, 14(4), 344352.

Nakamura, J. ve Csikszentmihalyi, M. (2005), The Concept of Flow. Handbook of Positive Psychology. Snyder Oxford: Oxford University Press: 89-105.

Öz, E. Ü. ve Bulutlar, F. (2009). Alg1lanan kurumsal itibar ve kurumdan ayrılma niyeti arasındaki ilişkide bir ara değişken olarak özdeşleşmenin rolü. Yönetim Araştırmaları Dergisi, 9(1), 35-52.

Rettie, R. (2001). An exploration of flow during Internet use. Internet Research, 11(2), 103-113. 
Riketta, M. ve Van Dick, R. (2005). Foci of attachment in organizations: a meta-analytic comparison of the strength and correlates of workgroup versus organizational identification and commitment.. Journal of Vocational Behavior, 67(3), 490-510.

Rousseau, D. M. (1998). Why workers still identify with organizations. Journal of Organizational Behavior: The International Journal of Industrial, Occupational and Organizational Psychology and Behavior, 19(3), 217-233.

Şimşek, E. ve Aktaş, H. (2014). Örguitsel sessizlik ile kişilik ve yaşam doyumu etkileşimi: kamu sektöründe bir araştırma. Anadolu Üniversitesi Sosyal Bilimler Dergisi, 14(2), 121-136.

Taşlıyan, M., Hırlak, B. ve Çiftçi, G. E. (2016). Farklılık yönetiminin örgütsel özdeşleşme üzerine etkisi: akademik ve idari personel üzerine bir araştırma. Elektronik Sosyal Bilimler Dergisi, 15(59), 1339-1359.

Walker, C. J. (2010). Experiencing flow: Is doing it together better than doing it alone?. The Journal of Positive Psychology, 5(1), 3-11.

\section{Kaynakça Bilgisi / Citation Information}

Fidanboy, C. Ö. (2019). Çalışanların yaşam doyumuna yönelik algıları, örgütsel özdeşleşme düzeyleri ve akış deneyimi arasındaki ilişkiler: Bilişim sektörü örneği. OPUS-Uluslararası Toplum Araştırmaları Dergisi, 12(18. UİK Özel Sayısı), 822-849. DOI: 10.26466/opus.583983 